\title{
NT-proBNP and Echocardiographic Parameters in Liver Cirrhosis: Correlations with Disease Severity
}

\author{
Alexandru Radu Mihailovici $^{\mathrm{a}} \quad$ Ionuț Donoiu $^{\mathrm{b}}$ Dan lonuț Gheoneac \\ Oana Mireab $^{b}$ Georgică Costinel Târtea ${ }^{d}$ Maria Buşe ${ }^{a} \quad$ Veronica Calborean $^{a}$ \\ Cosmin Obleagăe Vlad Pădureanu ${ }^{f}$ Octavian Istrătoaie ${ }^{b}$ \\ ${ }^{a}$ Department of Cardiology, Emergency County Hospital, Craiova, Romania; ${ }^{b}$ Department of Cardiology, University \\ of Medicine and Pharmacy, Craiova, Romania; ' Research Center of Gastroenterology and Hepatology, Craiova, \\ Romania; ${ }^{d}$ Department of Physiology, University of Medicine and Pharmacy, Craiova, Romania; ${ }^{e}$ Department of \\ Surgery, University of Medicine and Pharmacy, Craiova, Romania; ${ }^{\mathrm{f} D e p a r t m e n t ~ o f ~ I n t e r n a l ~ M e d i c i n e, ~ U n i v e r s i t y ~ o f ~}$ \\ Medicine and Pharmacy, Craiova, Romania
}

\section{Significance of the Study}

- NT-proBNP levels and echocardiographic parameters of cardiac dysfunction are correlated with cirrhosis severity, and could help establish prognosis. NT-proBNP could be used as a screening test in cirrhosis, with the intention of selecting patients in which cardiological consultation and echocardiography are required.

\section{Keywords}

NT-proBNP · Transthoracic echocardiography · Liver cirrhosis · Cardiac dysfunction · Cardiac biomarkers

\begin{abstract}
Objective: Liver cirrhosis is associated with several cardiovascular abnormalities including a hyperdynamic splanchnic and systemic circulation related to arterial vasodilatation, finally leading to sodium retention, central hypovolemia, and increased intravascular volume. The objective of this study was to evaluate the relationship between NT-proBNP and echocardiographic parameters and liver disease stage in patients with cirrhosis. Method: This prospective study included 82 consecutive patients diagnosed with liver cirrhosis and 120 healthy, age- and sex-matched subjects. Stan-
\end{abstract}

\begin{tabular}{ll}
\hline KARGER & $\begin{array}{l}\text { (c) 2019 The Author(s) } \\
\text { Published by S. Karger AG, Basel Openger }\end{array}$ \\
E-Mail karger@karger.com & $\begin{array}{l}\text { This is an Open Access article licensed under the Creative Commons } \\
\text { Attribution-NonCommercial-4.0 International License (CC BY-NC) } \\
\text { (http://www.karger.com/Services/OpenAccessLicense), applicable to } \\
\text { the online version of the article only. Usage and distribution for com- } \\
\text { mercial purposes requires written permission. }\end{array}$
\end{tabular}

dard transthoracic echocardiography was performed in all patients. Plasma NT-proBNP levels were determined. Liver disease severity in patients with cirrhosis was established by Child-Pugh class, MELD score and presence/absence of ascites. Results: Plasma levels of NT-proBNP were significantly higher in cirrhotic patients than the corresponding levels in the healthy subjects. NT-proBNP levels were also significantly elevated in Child-Pugh class $C$ patients compared to those in class $B$ and $A$. Left atrium (LA) size, diastolic function, left ventricular (LV) wall thickness, and LV ejection fraction were significantly altered in cirrhotic patients compared to controls. Advanced cirrhosis and high levels of NT-proBNP were significantly associated with increased LA volume and signs of cardiac diastolic dysfunction. We also observed significant differences between quartile groups of MELD score for the following: NT-proBNP, Troponin I, LA volume, left ventricle
Ionuț Donoiu

Department of Cardiology

University of Medicine and Pharmacy of Craiova

Petru Rareș Street nr. 2, RO-200349 Craiova (Romania)

E-Mail ionut.donoiu@umfcv.ro 
wall thickness, lateral wall and septum systolic tissue Doppler velocities and global longitudinal strain. Conclusion: NT-proBNP is increased in patients with cirrhosis and is correlated with the severity of liver disease as established by Child-Pugh class, MELD score, and the presence of ascites.

(C) 2019 The Author(s)

Published by S. Karger AG, Basel

\section{Introduction}

Cirrhosis is a diffuse and irreversible liver disease characterized by regenerative nodules surrounded by fibrous bands, leading to portal hypertension and ultimately liver failure. It is a major problem for the healthcare system because of high prevalence and mortality. Liver cirrhosis is a hyperdynamic condition characterized by increased cardiac output and decreased peripheral vascular resistance $[1,2]$. Because of this hemodynamic profile, a number of cardiac abnormalities can develop, leading to cirrhotic cardiomyopathy which includes abnormal contractile response to stress and/or altered diastolic relaxation with electrophysiological abnormalities, in the absence of known cardiac disease [3-5].

The natriuretic peptides that are released by cardiomyocytes in response to cardiac volume or pressure overload play an important role in the diagnosis of asymptomatic left ventricular (LV) dysfunction and also have a prognostic role in heart failure [6]. Furthermore, recent studies have shown that increased levels of NT-proBNP are present in patients with chronic liver disease, and particularly in ascitic cirrhosis [7-11] even in the absence of LV clinical dysfunction. Because they seem to be related to the severity of liver disease and of cardiac dysfunction, they could be useful markers to identify cirrhotic patients with increased cardiovascular risk and therefore poor prognosis.

This study was performed to evaluate the correlations between liver cirrhosis severity and cardiac function assessed through echocardiography and NT-proBNP.

\section{Material and Methods}

\section{Study Population}

This prospective study included 82 patients diagnosed with liver cirrhosis at different degrees of disease evolution, admitted to the Emergency County Hospital from Craiova between October 2015 and September 2016. The study group was age- and sexmatched with 120 healthy subjects without known history of cardiac, hepatic, or kidney disease.

NT-ProBNP and Cirrhotic

Cardiomyopathy
The inclusion criteria were: age over 25 years and diagnosis of cirrhosis confirmed by analysis of clinical and paraclinical data (laboratory examinations, abdominal ultrasound). Exclusion criteria were: known cardiac disease (including, but not restricted to: ischemic and non-ischemic cardiopathy, valvular heart disease, congenital heart disease, rhythm or conduction disorders, arterial hypertension, etc.) and patients with known kidney disease (including those with eGFR $<90 \mathrm{~mL} / \mathrm{min} / 1.73$ $\mathrm{m}^{2}$ ). Additionally, for the control group, a recent intake of drugs that could affect heart or liver function was considered exclusion criterion.

The study was reviewed and approved by the Institutional Review Board of the University of Medicine and Pharmacy of Craiova. All subjects gave informed consent to participate in the study.

Transthoracic echocardiography was performed on the first day of hospitalization, before paracentesis, using commercially available ultrasound equipment (Toshiba Aplio 400). Subjects were examined positioned in the left lateral decubitus and parasternal long axis views and apical 4-, 3-, 2-chamber views were recorded at a frame rate of minimum $60 \mathrm{fps}$, during breath hold. All measurements were done according to the American Society of Echocardiography and the European Association of Cardiovascular Imaging Recommendations for Cardiac Chamber Quantification by Echocardiography in Adults [12].

LV volumes were obtained from the apical 2- and 4-chamber projections. Ejection fraction was calculated using modified Simpson's rule. Additionally, systolic myocardial velocity derived from pulsed-wave Tissue Doppler imaging (TDI; Fig. 1a, b) were used for the evaluation of LV systolic function. Left atrium (LA) volume was measured from 4-chamber view in end-systole because in some patients, the biplane planimetry was not feasible due to suboptimal 2-chamber LA visualization. This method usually underestimates LA volume but has shown a good correlation with the biplane method and 3-dimensional echocardiography measurements [13]. Early (E) and late (A) peak velocities and their ratio were calculated. The ratio between $\mathrm{E}$ and early ( $\left.\mathrm{e}^{\prime}\right)$ diastolic mean (septal and lateral mitral annulus) TDI velocity was used to estimate LV filling pressures.

For grading diastolic dysfunction, we used the echocardiographic criteria latest updated by American Society of Echocardiography in collaboration with European Association for Cardiovascular Imaging: grade I dysfunction $-\mathrm{E} \leq 50 \mathrm{~cm} / \mathrm{s}$ and $\mathrm{E} / \mathrm{A} \leq 0.8$; grade II $-\mathrm{E}>50 \mathrm{~cm} / \mathrm{s}$ and $\mathrm{E} / \mathrm{A} \leq 0.8$ or $\mathrm{E} / \mathrm{A}=0.8-2$, and at least 2 criteria of the following: $\mathrm{E} / \mathrm{e}^{\prime}=10-14$, tricuspid regurgitation velocity $>2.8 \mathrm{~m} / \mathrm{s}$ and/or LA indexed volume $>34 \mathrm{~mL} / \mathrm{m}^{2}$; grade III $-\mathrm{E} / \mathrm{A}>2$ [14].

Myocardial deformation was analyzed using an 18 segments model. The beginning of systole was set as the frame of mitral valve closure, whereas end-systole was defined as the end of the aortic flow from the pulsed-wave Doppler recording from the LV out-flow tract. The analysis was performed by manually tracking the endocardium border and adjusting the range of interest according to the myocardial thickness. LV global longitudinal strain (GLS) values for the myocardial layer were measured.

\section{Laboratory Tests}

Blood was drawn immediately after hospitalization from a forearm vein after at least $10 \mathrm{~min}$ of resting supine, collected in standard sampling tubes for NT-proBNP and troponin analysis, and in appropriate tubes for other laboratory determinations. A 


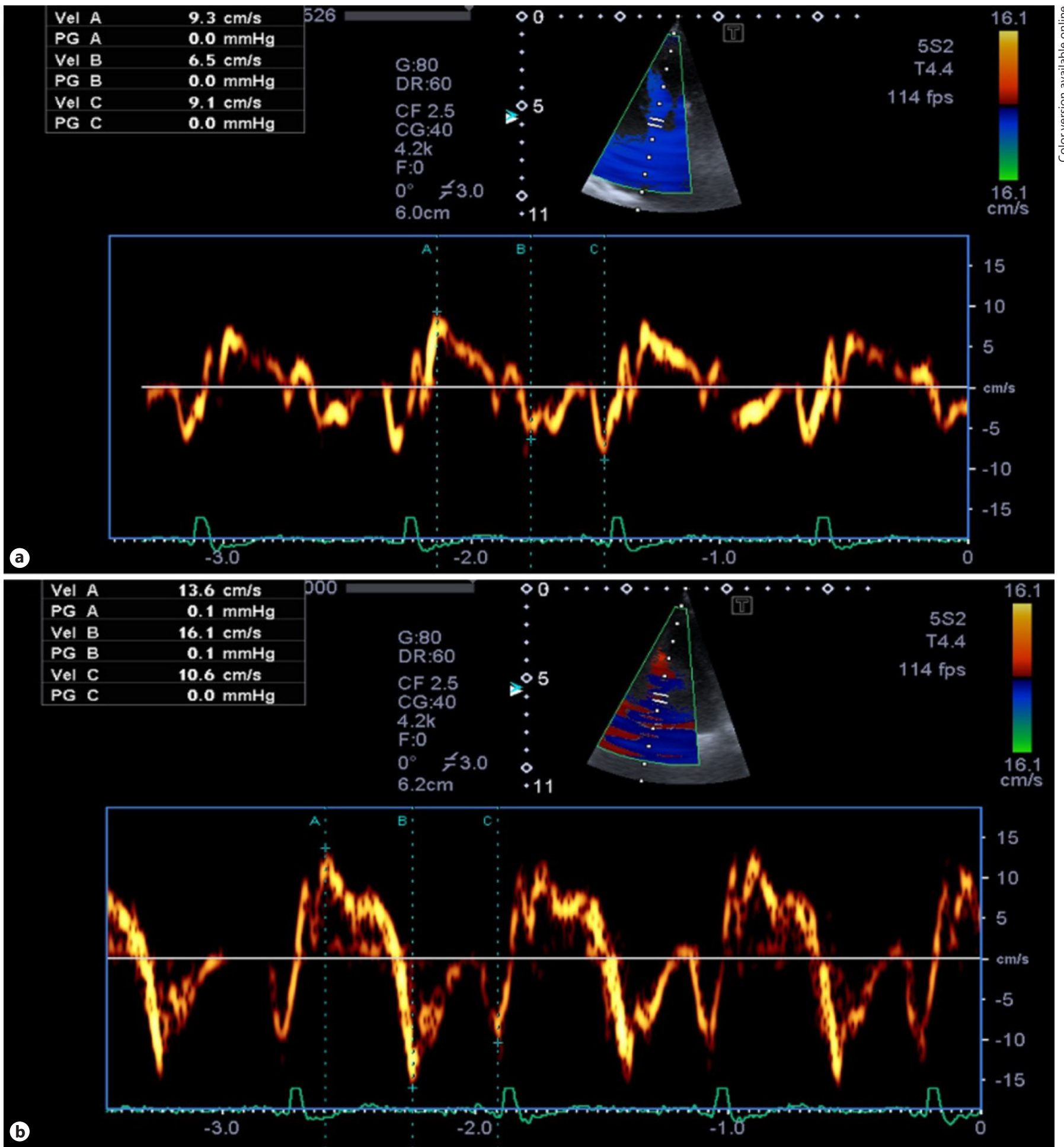

Fig. 1. Doppler Tissue Imaging of mitral annular motion at the septal level. In patients with liver cirrhosis included in our study (a), we found low velocities of the systolic and diastolic waves at the septal level (e.g., $\mathrm{S}=$ $9.3 \mathrm{~cm} / \mathrm{s}, \mathrm{e}^{\prime}=6.5 \mathrm{~cm} / \mathrm{s}$ and $\mathrm{a}^{\prime}=9.1 \mathrm{~cm} / \mathrm{s}$ ) compared to healthy subjects $(\mathbf{b})$ included in the control group ( $=$ $13.6 \mathrm{~cm} / \mathrm{s}, \mathrm{e}^{\prime}=16.1 \mathrm{~cm} / \mathrm{s}$ and $\left.\mathrm{a}^{\prime}=10.6 \mathrm{~cm} / \mathrm{s}\right) . \mathbf{a}=\mathrm{S}$ wave, $\mathbf{b}=\mathrm{e}^{\prime}$ wave and $\mathbf{c}=\mathrm{a}^{\prime}$ wave. 
Table 1. General characteristics of the subjects

\begin{tabular}{lccc}
\hline Variables & $\begin{array}{c}\text { Control group } \\
(120 \text { subjects })\end{array}$ & $\begin{array}{c}\text { Cirrhosis group } \\
(82 \text { patients })\end{array}$ & $p$ value \\
\hline Age, years & $56.5 \pm 13.4$ & $55.2 \pm 9.5$ & ns \\
Males, \% & 62.5 & 61 & $\mathrm{~ns}$ \\
BMI, kg/m ${ }^{2}$ & $25.7 \pm 3.9$ & $26.6 \pm 3.4$ & $\mathrm{~ns}$ \\
Heart rate, bpm & $68.60 \pm 10.22$ & $81.05 \pm 19.26$ & 0.0003 \\
Systolic BP, mm Hg & $115.3 \pm 11.41$ & $105.8 \pm 18.39$ & 0.0016 \\
Diastolic BP, mm Hg & $71.75 \pm 6.74$ & $76.11 \pm 10.67$ & $\mathrm{~ns}$ \\
Creatinine, mg/dL & $0.84 \pm 0.16$ & $1.05 \pm 1.31$ & $\mathrm{~ns}$ \\
Urea, mg/dL & $37.90 \pm 6.04$ & $42.44 \pm 31.60$ & $\mathrm{~ns}$ \\
INR & $1.09 \pm 0.11$ & $1.80 \pm 0.7$ & $<0.0001$ \\
Serum AST, U/L & $23.99 \pm 6.11$ & $87.32 \pm 78.55$ & $<0.0001$ \\
Serum ALT, U/L & $17.40 \pm 3.89$ & $46.22 \pm 35.27$ & $<0.0001$ \\
Serum GGT, U/L & $24.10 \pm 10.51$ & $171.8 \pm 207.3$ & $<0.0001$ \\
Total serum bilirubin, mg/dL & $0.67 \pm 0.12$ & $5.06 \pm 4.25$ & $<0.0001$ \\
Direct serum bilirubin, mg/dL & $0.48 \pm 0.11$ & $3.01 \pm 2.83$ & $<0.0001$ \\
Serum albumin, g/dL & $4.56 \pm 0.5$ & $3.26 \pm 0.4$ & $<0.0001$ \\
Serum sodium, mmol/L & $142.2 \pm 5$ & $135.1 \pm 8$ & $<0.0001$ \\
Serum potassium, mmol/L & $4.2 \pm 0.6$ & $4.1 \pm 0.8$ & $\mathrm{~ns}$ \\
Diuretics, \% & - & 62 & - \\
Betablocker, \% & - & 39 & - \\
& & &
\end{tabular}

Data are expressed as means $\pm \mathrm{SD}$.

BMI, body mass index; BP, blood pressure; INR, international normalized ratio; AST, aspartate aminotransferase; ALT, alanine aminotransferase; GGT, gamma-glutamyltransferase; ns, not significant.
Table 2. Comparison of cardiac variables between control and test groups

\begin{tabular}{lccc}
\hline Variables & $\begin{array}{c}\text { Control group } \\
(120 \text { subjects) }\end{array}$ & $\begin{array}{c}\text { Cirrhosis group } \\
(82 \text { patients })\end{array}$ & $p$ value \\
\hline NT-proBNP, pg/mL & $42.6 \pm 32.5$ & $416.8 \pm 266.5$ & $<0.0001$ \\
TnI, ng/mL & $0.0011 \pm 0.0010$ & $0.0129 \pm 0.0357$ & $\mathrm{~ns}$ \\
LAD, mm & $30.0 \pm 2.4$ & $38.5 \pm 5.3$ & $<0.0001$ \\
LA volume, mL & $27.0 \pm 2.1$ & $35.2 \pm 5.1$ & $<0.0001$ \\
IVST, mm & $10.1 \pm 1.5$ & $11.0 \pm 1.7$ & 0.0242 \\
PWT, mm & $10.1 \pm 0.8$ & $9.9 \pm 1.3$ & $\mathrm{~ns}$ \\
LVDD, mm & $46.6 \pm 3.6$ & $49.2 \pm 6.7$ & $\mathrm{~ns}$ \\
LVSD, mm & $39.8 \pm 5.0$ & $37.1 \pm 7.7$ & $\mathrm{~ns}$ \\
RVD, mm & $29.7 \pm 1.5$ & $32.6 \pm 7.7$ & $\mathrm{~ns}$ \\
RAD, mm & $34.2 \pm 2.2$ & $38.1 \pm 6.3$ & 0.0086 \\
E wave, m/s & $0.97 \pm 0.13$ & $0.65 \pm 0.19$ & $<0.0001$ \\
A wave, m/s & $0.62 \pm 0.07$ & $0.64 \pm 0.17$ & $\mathrm{~ns}$ \\
E/A & $1.5 \pm 0.15$ & $1.06 \pm 0.43$ & $<0.0001$ \\
EDT, ms & $214.3 \pm 17.3$ & $218.3 \pm 42.7$ & $\mathrm{~ns}$ \\
e' septal, cm/s & $12.3 \pm 1.3$ & $9.6 \pm 7.3$ & $\mathrm{~ns}$ \\
e' lateral, cm/s & $16.4 \pm 1.3$ & $11.1 \pm 4.0$ & $<0.0001$ \\
E/e' & $6.8 \pm 0.4$ & $7.2 \pm 2.4$ & $\mathrm{~ns}$ \\
S septal, cm/s & $13.1 \pm 1.1$ & $9.1 \pm 2.3$ & $<0.0001$ \\
S lateral, cm/s & $15.5 \pm 1.0$ & $10.4 \pm 2.2570$ & $<0.0001$ \\
GLS, \% & $-22.4 \pm 1.8$ & $-18.8 \pm 4.1$ & 0.0004 \\
LVEF, \% & $56.5 \pm 4.3$ & $48.0 \pm 9.5$ & 0.0002 \\
\hline
\end{tabular}

Data are expressed as means \pm SD.

TnI, troponin I; LAD, left atrium diameter; LA, left atrium; IVST, interventricular septum thickness; PWT, posterior wall thickness; LVDD, left ventricle diastolic diameter; LVSD, left ventricle systolic diameter; RVD, right ventricle diameter; RAD, right atrium diameter; EDT, E wave deceleration time; GLS, global longitudinal strain; LVEF, left ventricular ejection fraction; ns, not significant. 


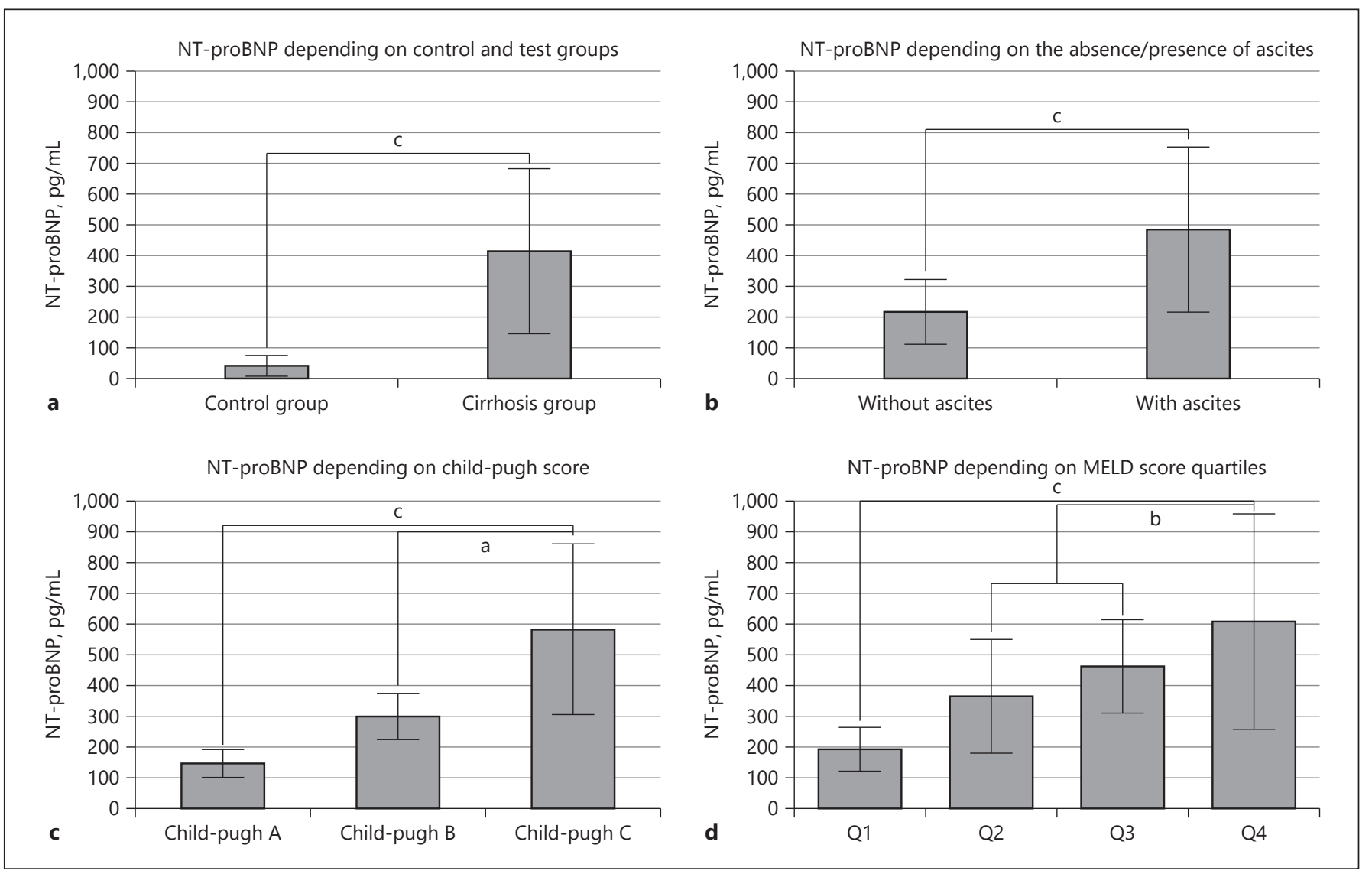

Fig. 2. NT-proBNP depending on clinicopathological features. Cirrhotic patients showed significantly higher plasma levels of NT-proBNP than controls (a). We also observed that plasma levels of NT-proBNP increase with the severity of liver cirrhosis assessed by the presence/absence of ascites (b), Child-Pugh class (c) or MELD score (d). a-c Represent statistical significance on $t$ test or one-way analysis of variance with post hoc comparisons using the Bonferroni's test $(p<0.05, p<0.01$ and respectively $p<0.001)$. Error bars represent SD of the mean.

complete blood count, prothrombin time, and liver and renal function tests were performed using standard laboratory automated techniques.

Plasma levels of NT-proBNP were determined by commercial analysis (Vitros NT-proBNP, Ortho-Clinical Diagnostics, Inc.). Blood samples from cirrhotic patients and controls were centrifuged at 2,000 $\mathrm{rpm}$ for $15 \mathrm{~min}$ at room temperature. The supernatant plasma was recovered and stored at $-80{ }^{\circ} \mathrm{C}$ until analysis.

Troponin I (TnI) was measured using the cTNI Flex reagent cartridge on a Dimension Vista ${ }^{\circledR}$ System, Siemens Healthcare Diagnostics The lowest measurement on the cTNI Flex cartridge is $0.02 \mathrm{ng} / \mathrm{mL}$; values above $0.05 \mathrm{ng} / \mathrm{mL}$ were considered elevated.

All the variables were measured before paracentesis, except body mass index, which was calculated after paracentesis. Prior medication of patients was not stopped prior to measurements.

Statistical analysis was performed using XLSTAT 2014 for MS Excel (Addinsoft SARL, Paris, France) and SPSS software (IBM SPSS Statistics, version 20.0). Results are reported as mean \pm SD. The Student $t$ test was used to compare the continuous variables when the normality hypothesis was met; if not, nonparametric tests (Mann-Whitney or Kruskal-Wallis) were performed. We also used one-way ANOVA with Bonferroni's post hoc analysis in order to compare the means of more than 2 groups. The categorical variables were analyzed using chi-square test or Fisher's F test, as appropriate. A $p<0.05$ value was considered statistically significant for the comparison of several groups.

\section{Results}

\section{Clinicopathological Features}

The demographical, clinical, and standard biological characteristics of the subjects are presented in Table 1.

The study group included 82 patients diagnosed with cirrhosis (61\% men, mean age 55.2 \pm 9.5$)$. Most patients (80.4\%) had alcoholic cirrhosis, and of those with viral 
Table 3. Biological and echocardiography parameters depending on MELD score quartiles

\begin{tabular}{|c|c|c|c|c|c|}
\hline Variable & Q1 & Q2 & Q3 & Q4 & $\begin{array}{l}p \text { value } \\
\text { Kruskal-Wallis }\end{array}$ \\
\hline Age, years & $51.6 \pm 11.9$ & $56.0 \pm 9.1$ & $58.0 \pm 9.4$ & $55.0 \pm 7.4$ & ns \\
\hline NT-proBNP, pg/mL & $188.0 \pm 72.6$ & $365.0 \pm 186.2$ & $460.0 \pm 155.6$ & $607.6 \pm 349.0$ & $<0.0001$ \\
\hline TnI, ng/mL & $0.0008 \pm 0.0009$ & $0.0053 \pm 0.0067$ & $0.0160 \pm 0.0213$ & $0.0267 \pm 0.0626$ & $<0.0001$ \\
\hline $\mathrm{LAD}, \mathrm{mm}$ & $35.8 \pm 4.3$ & $38.6 \pm 4.3$ & $40.5 \pm 6.0$ & $38.8 \pm 5.7$ & ns \\
\hline IVST, mm & $10.8 \pm 1.7$ & $10.3 \pm 2.0$ & $12.0 \pm 1.1$ & $11.1 \pm 1.6$ & 0.0189 \\
\hline PWT, mm & $9.5 \pm 1.1$ & $8.9 \pm 0.6$ & $11.1 \pm 1.5$ & $10.2 \pm 1.1$ & $<0.0001$ \\
\hline LVDD, mm & $48.0 \pm 7.2$ & $49.5 \pm 5.2$ & $50.9 \pm 9.2$ & $48.5 \pm 5.0$ & ns \\
\hline LVSD, mm & $36.7 \pm 6.6$ & $34.1 \pm 7.0$ & $40.6 \pm 9.7$ & $37.1 \pm 6.2$ & ns \\
\hline $\mathrm{RVD}, \mathrm{mm}$ & $29.3 \pm 12.2$ & $31.8 \pm 6.3$ & $35.1 \pm 5.5$ & $33.9 \pm 4.9$ & ns \\
\hline $\mathrm{RAD}, \mathrm{mm}$ & $38.2 \pm 5.6$ & $35.5 \pm 4.6$ & $39.6 \pm 8.2$ & $38.9 \pm 6.0$ & ns \\
\hline e' septal, $\mathrm{cm} / \mathrm{s}$ & $9.3 \pm 3.0$ & $8.4 \pm 2.7$ & $11.4 \pm 14.1$ & $9.4 \pm 2.4$ & ns \\
\hline e' lateral, $\mathrm{cm} / \mathrm{s}$ & $12.1 \pm 4.5$ & $10.0 \pm 2.2$ & $10.2 \pm 3.6$ & $12.2 \pm 4.9$ & ns \\
\hline $\mathrm{E} / \mathrm{e}^{\prime}$ & $6.9 \pm 1.4$ & $7.6 \pm 3.0$ & $7.6 \pm 3.2$ & $6.7 \pm 1.6$ & ns \\
\hline S septal, $\mathrm{cm} / \mathrm{s}$ & $9.7 \pm 2.4$ & $8.7 \pm 1.9$ & $7.6 \pm 1.6$ & $10.3 \pm 2.3$ & 0.0003 \\
\hline$S$ lateral, $\mathrm{cm} / \mathrm{s}$ & $11.5 \pm 1.8$ & $9.7 \pm 2.1$ & $10.1 \pm 2.3$ & $10.3 \pm 2.3$ & 0.0252 \\
\hline GLS, $\%$ & $-18.4 \pm 3.8$ & $-21.0 \pm 3.2$ & $-15.9 \pm 3.2$ & $-19.9 \pm 4.5$ & 0.0010 \\
\hline LVEF, \% & $47.1 \pm 8.7$ & $48.3 \pm 7.5$ & $44.2 \pm 12.5$ & $52.0 \pm 7.4$ & ns \\
\hline
\end{tabular}

Data are expressed as means \pm SD.

BMI, body mass index; TnI, troponin I; LAD, left atrium diameter; LA, left atrium; IVST, interventricular septum thickness; PWT, posterior wall thickness; LVDD, left ventricle diastolic diameter; LVSD, left ventricle systolic diameter; RVD, right ventricle diameter; RAD, right atrium diameter; EDT, E wave deceleration time; GLS, global longitudinal strain; LVEF, left ventricular ejection fraction; ns, not significant.

Fig. 3. Diastolic function profiles in the control group compared to the cirrhosis group. a-c Represent statistical significance on $t$ test or one-way analysis of variance with post hoc comparisons using the Bonferroni's test $(p<0.05, p<0.01$ and respectively $p<0.001)$.

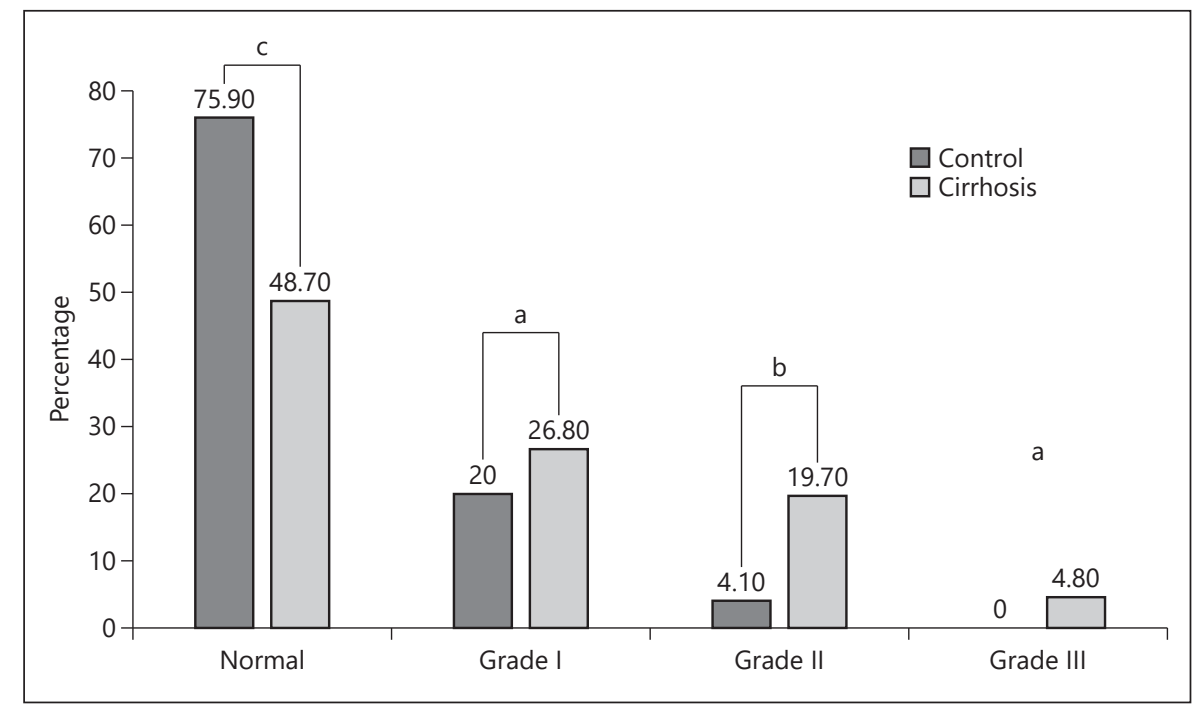

NT-ProBNP and Cirrhotic Cardiomyopathy
Med Princ Pract 2019;28:432-441 DOI: $10.1159 / 000499930$ 
etiology 3 quarters (almost $14.6 \%$ of the total) had viral hepatitis B, the rest of $4.8 \%$ with etiology of viral hepatitis C. According to Child-Pugh classification, the distribution of patients was as follows: 14 patients (17.07\%) in class A; 26 patients (31.71\%) in Class B and the remaining 42 patients (51.22\%) in Class C. Furthermore, all 82 patients were subdivided according to the presence or absence of ascites; 62 of $82(75.6 \%)$ were patients with ascites being on diuretic therapy or required paracentesis; the remaining $20(24.4 \%)$ were without ascites.

\section{NT-proBNP and Echocardiographic Changes Based on} Clinicopathological Features

As can be seen in Table 2, cirrhotic patients showed significantly higher plasma levels of NT-proBNP than controls (Fig. 2a). LA diameter and volume, right atrium diameter, diastolic function (as estimated by transmitral flow pattern and Tissue Doppler), and systolic function (LV ejection fraction and GLS) were significantly altered in patients with cirrhosis compared to controls. Diastolic dysfunction was more frequent, and it was significantly more severe in the cirrhosis group (Fig. 3).

To ascertain whether there is a relationship between echocardiography abnormalities or NT-proBNP levels (Fig. 2b-d) and the severity of liver disease in the group with cirrhosis, we analyzed their relation to MELD score, Child-Pugh class, or the presence/absence of ascites. We observed significant differences between quartile groups of MELD score for the following: NT-proBNP, TnI, LA volume, left ventricle wall thickness, lateral wall and septum systolic tissue Doppler velocities, and GLS (Table 3). We analyzed the correlations between the studied parameters and MELD score (Table 4); the only significant results were for NT-proBNP $(r=0.49, p<0.0001)$ and LA volume $(r=0.3, p=0.0091)$.

Child-Pugh classification is used for the prognosis of patients with liver cirrhosis. We analyzed the statistical differences between the variables measured by ChildPugh class. As can be seen in Table 5, several clinical-biological parameters correlated significantly with the Child-Pugh class. The presence of a direct correlation among NT-proBNP, TnI, and LA volume with the severity of cirrhosis is noteworthy.

Finally, we compared patients depending on the presence of ascites. Patients with ascites had significantly higher levels of NT-proBNP and TnI, LA enlargement, right heart enlargement, lower TDI lateral mitral annulus e', and higher LV ejection fraction (Table 6).
Table 4. Correlations of studied parameters with MELD score

\begin{tabular}{|c|c|c|}
\hline Variable & $\begin{array}{l}\text { Pearson's } \\
\text { correlation }\end{array}$ & $p$ value \\
\hline Age, years & -0.0437 & ns \\
\hline BMI, kg/m² & -0.0412 & ns \\
\hline NT-proBNP & 0.4914 & $<0.0001$ \\
\hline TnI & 0.1432 & ns \\
\hline LAD & 0.1435 & ns \\
\hline LA volume & 0.3054 & 0.0091 \\
\hline IVST & -0.0373 & ns \\
\hline PWT & 0.1768 & ns \\
\hline LVDD & 0.0273 & ns \\
\hline LVSD & 0.0778 & ns \\
\hline RVD & 0.2072 & ns \\
\hline RAD & 0.1443 & ns \\
\hline E wave & 0.0279 & ns \\
\hline A wave & -0.0089 & ns \\
\hline $\mathrm{E} / \mathrm{A}$ & 0.1222 & ns \\
\hline EDT & 0.0490 & ns \\
\hline e' septal & -0.0128 & ns \\
\hline e' lateral & 0.1690 & ns \\
\hline $\mathrm{E} / \mathrm{e}^{\prime}$ & -0.1305 & ns \\
\hline S septal & 0.1820 & ns \\
\hline S lateral & -0.0626 & ns \\
\hline GLS & -0.0122 & ns \\
\hline LVEF & 0.1993 & ns \\
\hline
\end{tabular}

BMI, body mass index; TnI, troponin I; LAD, left atrium diameter; LA, left atrium; IVST, interventricular septum thickness; PWT, posterior wall thickness; LVDD, left ventricle diastolic diameter; LVSD, left ventricle sys-tolic diameter; RVD, right ventricle diameter; RAD, right atrium diameter; EDT, E wave deceleration time; GLS, global longitudinal strain; LVEF, left ventricular ejection fraction; ns, not significant

\section{Discussion}

In this study, we observed an increase in levels of NTproBNP as well as echocardiographic changes such as increased LA volume and lower ejection fraction in patients with cirrhosis compared to the control group. There is a strong correlation between NT-proBNP and atrial volumes. We also noticed that patients with ascites compared to those without ascites had elevated levels of NTproBNP and higher atrial volumes. These findings could be the expression of the hyperdynamic syndrome $[5,6$, 10]. Levels of NT-proBNP were increased in the presence of ascites, probably due to increased fluid retention in these patients. Ascitic patients also had higher atrial volumes. These data suggest that NT-proBNP could be used as a marker of subclinical cardiac dysfunction involved in hepatic decompensation. A study by Henriksen et al. [7] 
Table 5. Relation of studied variables depending on Child-Pugh class of liver cirrhosis

\begin{tabular}{|c|c|c|c|c|}
\hline Variable & Child-Pugh A & Child-Pugh B & Child-Pugh C & $\begin{array}{l}p \text { value } \\
\text { Kruskal-Wallis }\end{array}$ \\
\hline Age, years & $54.3 \pm 13.3$ & $52.5 \pm 9.2$ & $57.3 \pm 7.9$ & ns \\
\hline $\mathrm{BMI}, \mathrm{kg} / \mathrm{m}^{2}$ & $27.7 \pm 5.6$ & $24.9 \pm 2.7$ & $27.4 \pm 2.4$ & 0.0043 \\
\hline NT-proBNP, pg/mL & $147.0 \pm 45.1$ & $301.9 \pm 76.3$ & $583.3 \pm 277.6$ & $<0.0001$ \\
\hline TnI, ng/mL & $0.0012 \pm 0.0013$ & $0.0045 \pm 0.0071$ & $0.0224 \pm 0.0486$ & $<0.0001$ \\
\hline $\mathrm{LAD}, \mathrm{mm}$ & $35.8 \pm 3.1$ & $38.6 \pm 5.5$ & $39.4 \pm 5.6$ & ns \\
\hline LA volume, $\mathrm{mL}$ & $33.8 \pm 3.2$ & $31.9 \pm 3.7$ & $37.8 \pm 5.0$ & $<0.0001$ \\
\hline IVST, mm & $10.0 \pm 1.4$ & $10.9 \pm 1.9$ & $11.5 \pm 1.5$ & 0.0342 \\
\hline PWT, mm & $9.7 \pm 1.1$ & $9.0 \pm 0.9$ & $10.6 \pm 1.3$ & $<0.0001$ \\
\hline LVDD, mm & $47.6 \pm 5.8$ & $50.0 \pm 6.2$ & $49.2 \pm 7.4$ & ns \\
\hline LVSD, mm & $36.6 \pm 5.7$ & $36.4 \pm 8.2$ & $37.8 \pm 8.0$ & ns \\
\hline $\mathrm{RVD}, \mathrm{mm}$ & $25.6 \pm 11.3$ & $33.6 \pm 6.8$ & $34.3 \pm 5.4$ & 0.0238 \\
\hline $\mathrm{RAD}, \mathrm{mm}$ & $34.1 \pm 3.2$ & $38.5 \pm 5.4$ & $39.1 \pm 7.2$ & 0.0445 \\
\hline E wave, $\mathrm{m} / \mathrm{s}$ & $0.62 \pm 0.18$ & $0.71 \pm 0.18$ & $0.62 \pm 0.19$ & ns \\
\hline A wave, $\mathrm{m} / \mathrm{s}$ & $0.62 \pm 0.15$ & $0.63 \pm 0.14$ & $0.66 \pm 0.20$ & ns \\
\hline $\mathrm{E} / \mathrm{A}$ & $1.04 \pm 0.32$ & $1.14 \pm 0.25$ & $1.02 \pm 0.54$ & ns \\
\hline EDT, ms & $218.0 \pm 33.9$ & $197.7 \pm 36.4$ & $232.1 \pm 44.5$ & 0.0054 \\
\hline e' septal, $\mathrm{cm} / \mathrm{s}$ & $9.3 \pm 3.4$ & $9.0 \pm 2.6$ & $10.2 \pm 10.0$ & ns \\
\hline e' lateral, $\mathrm{cm} / \mathrm{s}$ & $11.4 \pm 4.9$ & $12.5 \pm 4.4$ & $10.1 \pm 3.1$ & ns \\
\hline $\mathrm{E} / \mathrm{e}^{\prime}$ & $6.5 \pm 1.4$ & $7.4 \pm 2.7$ & $7.3 \pm 2.4$ & ns \\
\hline $\mathrm{S}$ septal, $\mathrm{cm} / \mathrm{s}$ & $10.1 \pm 2.6$ & $8.7 \pm 1.7$ & $9.0 \pm 2.4$ & ns \\
\hline$S$ lateral, $\mathrm{cm} / \mathrm{s}$ & $12.1 \pm 1.9$ & $9.7 \pm 1.6$ & $10.2 \pm 2.4$ & 0.0084 \\
\hline GLS, \% & $-19.2 \pm 4.9$ & $-19.6 \pm 3.3$ & $-18.2 \pm 4.4$ & ns \\
\hline LVEF, \% & $48.3 \pm 11.8$ & $47.2 \pm 5.3$ & $48.5 \pm 11.0$ & ns \\
\hline
\end{tabular}

Data are expressed as means $\pm \mathrm{SD}$.

BMI, body mass index; TnI, troponin I; LA, left atrium diameter; LA, left atrium; IVST, interventricular septum thickness; PWT, posterior wall thickness; LVDD, left ventricle diastolic diameter; LVSD, left ventricle systolic diameter; RVD, right ventricle diameter; RAD, right atrium diameter; EDT, E wave deceleration time; GLS, global longitudinal strain; LVEF, left ventricular ejection fraction; ns, not significant.

showed that NT-proBNP level is significantly increased in patients with advanced cirrhosis and that it is closely related to BNP concentrations; however, in cirrhotic patients, there were no signs of reduced hepatic degradation of NT-proBNP or BNP, suggesting that high values of NT-proBNP and BNP are related to cirrhosis severity markers, indicating the presence of cardiac dysfunction in advanced cirrhosis. Compared to other tests that are costly and often do not correlate well with patient symptoms, natriuretic peptides are important diagnostic markers also assessing the severity and prognosis in heart failure. Type B of the natriuretic peptide (BNP) is a neurohormone synthesized in the ventricles. BNP originates from its pre-proBNP precursor, subsequently cleaved enzymatically in NT-proBNP, depending on the extent of ventricular myocytes mechanical stress [15]. In heart failure, circulating levels of BNP are constantly increased [16]. The measurement of plasma BNP and NT-proBNP was shown to be of diagnostic value in congestive heart failure. Moreover, they could be used to adjust treatment, and have been shown to be strong prognostic markers in acute and chronic heart failure independent of standard echocardiographic parameters $[6,17,18]$. NT-proBNP is influenced by age and glomerular filtration rate. The normal values are $<125 \mathrm{pg} / \mathrm{mL}$ in patients younger than 75 years, and $<450 \mathrm{pg} / \mathrm{mL}$ in patients over 75 years [15]. Despite this influence of age and kidney function, NTproBNP is considered to be a much better marker of cardiac dysfunction compared to BNP, as it is more stable, and less sensitive to rapid fluctuations due to short-term stimulus secretion [19].

The prognostic value of other markers of cardiac dysfunction or inflammation has been investigated in a study by Wiese et al. [20], which found significant association with disease severity, degree of portal hypertension and survival in cirrhosis for soluble urokinase-type plasminogen activator receptor and high sensitivity Troponin T. In our study, TnI was not significantly changed in cirrhosis 
Table 6. Parameters values depending on the absence/presence of ascites

\begin{tabular}{lccl}
\hline Variable & $\begin{array}{l}\text { Without } \\
\text { ascites }\end{array}$ & $\begin{array}{l}\text { With } \\
\text { ascites }\end{array}$ & $\begin{array}{l}\text { p value } \\
\text { Mann- } \\
\text { Whitney }\end{array}$ \\
\hline MELD score & $40.6 \pm 8.7$ & $62.3 \pm 22.5$ & $<0.0001$ \\
Age, years & $53.6 \pm 13.1$ & $55.8 \pm 7.8$ & ns \\
BMI, kg/m & $26.5 \pm 4.6$ & $26.7 \pm 2.8$ & ns \\
NT-proBNP, pg/mL & $222.1 \pm 108.6$ & $491.6 \pm 271.8$ & $<0.0001$ \\
TnI, ng/mL & $0.0031 \pm 0.0059$ & $0.0167 \pm 0.0413$ & 0.0022 \\
LAD, mm & $36.1 \pm 4.1$ & $39.5 \pm 5.5$ & 0.0145 \\
LA volume, mL & $31.9 \pm 3.3$ & $36.4 \pm 5.1$ & 0.0002 \\
IVST, mm & $10.9 \pm 2.1$ & $11.1 \pm 1.5$ & ns \\
PWT, mm & $9.5 \pm 1.1$ & $10.1 \pm 1.4$ & ns \\
LVDD, mm & $49.9 \pm 6.1$ & $49.0 \pm 7.0$ & ns \\
LVSD, mm & $38.5 \pm 5.7$ & $36.6 \pm 8.3$ & ns \\
RVD, mm & $26.7 \pm 9.7$ & $35.0 \pm 5.3$ & 0.0001 \\
RAD, mm & $35.1 \pm 3.9$ & $39.2 \pm 6.7$ & 0.0236 \\
E wave, m/s & $0.68 \pm 0.19$ & $0.63 \pm 0.18$ & ns \\
A wave, m/s & $0.63 \pm 0.17$ & $0.65 \pm 0.17$ & ns \\
E/A & $1.1 \pm 0.2$ & $1.0 \pm 0.4$ & ns \\
TDE, ms & $206.4 \pm 34.6$ & $222.9 \pm 44.9$ & ns \\
e' septal, cm/s & $9.7 \pm 3.1$ & $9.6 \pm 8.5$ & ns \\
e' lateral, cm/s & $13.2 \pm 4.3$ & $10.3 \pm 3.6$ & 0.0036 \\
E/e' & $6.5 \pm 2.2$ & $7.5 \pm 2.4$ & ns \\
S septal, cm/s & $9.0 \pm 2.3$ & $9.1 \pm 2.2$ & ns \\
S lateral, cm/s & $11.1 \pm 2.0$ & $10.1 \pm 2.2$ & ns \\
GLS, \% & $-17.9 \pm 3.4$ & $-19.2 \pm 4.4$ & ns \\
LVEF, \% & $46.1 \pm 9.2$ & $48.8 \pm 9.6$ & 0.0351 \\
\hline
\end{tabular}

Data are expressed as means \pm SD.

BMI, body mass index; TnI, troponin I; LAD, left atrium diameter; LA, left atrium; IVST, in-terventricular septum thickness; PWT, posterior wall thickness; LVDD, left ventricle diastolic diameter; LVSD, left ventricle systolic diameter; RVD, right ventricle diameter; RAD, right atrium diameter; EDT, E wave deceleration time; GLS, global longitudinal strain; LVEF, left ventricular ejection fraction; ns, not significant.

compared to the control group, but it was increased in more severe cases. This could also be a marker of myocardial damage [21].

In our study, the prevalence of diastolic dysfunction in patients with cirrhosis was $51.3 \%$, in most cases being mild. Diastolic dysfunction is a known feature in cirrhosis $[22,23]$. Its pathophysiological substratum is probably increased stiffness of the myocardial wall, most likely due to a combination of mild myocardial hypertrophy, fibrosis, and subendothelial edema [24]. The results of studies reporting diastolic dysfunction in patients with cirrhosis are conflicting. In some studies, diagnosis of diastolic dysfunction was mainly based on the modification of mitral flow variables $[25,26]$. The ratio between early and late left ventricle diastolic filling (E/A), commonly used for estimating diastolic function in medical practice is often prone to errors and is largely dependent on preload. In the case of abnormal LV relaxation and increased left atrial pressure, a pseudo-normalization of the mitral influx may occur, which masks the presence of diastolic dysfunction. The use of TDI may overcome some of these problems because this method is less influenced by changes in ventricular filling [27-29].

The primary limitation of this study is the relatively small number of patients. Second, since most patients had alcoholic cirrhosis, a possible co-existence of alcoholic myocardial dysfunction in some cases cannot be excluded. In fact, this could partly explain the relatively low LV ejection fraction in the cirrhosis group. Further prospective studies with serial measurements of LVEF would be valuable. Finally, direct hemodynamic assessment of splanchnic or systemic circulation was not done, so we do not have data about cardiac output, systemic vascular resistance, or portal venous pressure.

\section{Conclusions}

Our study has shown that patients with cirrhosis have echocardiographic (increased LA volume) and biochemical (higher levels of NT-proBNP) signs of subclinical cardiac dysfunction, directly related to liver disease severity.

\section{Disclosure Statement}

The authors declare that they have no conflicts of interest to disclose.

References

1 Iwakiri Y, Groszmann RJ. The hyperdynamic circulation of chronic liver diseases: from the patient to the molecule. Hepatology. 2006 Feb;43(2 Suppl 1):S121-31.

2 Liu H, Gaskari SA, Lee SS. Cardiac and vascular changes in cirrhosis: pathogenic mechanisms. World J Gastroenterol. 2006 Feb 14; 12(6):837-42.

3 Møller S, Henriksen JH. Cardiovascular complications of cirrhosis. Gut. 2008 Feb;57(2): 268-78.

4 Møller S, Henriksen JH. Cirrhotic cardiomyopathy. J Hepatol. 2010 Jul;53(1):179-90.

5 Zardi EM, Abbate A, Zardi DM, Dobrina A, Margiotta D, Van Tassell BW, et al. Cirrhotic cardiomyopathy. J Am Coll Cardiol. 2010 Aug;56(7):539-49. 
6 de Lemos JA, McGuire DK, Drazner MH. B-type natriuretic peptide in cardiovascular disease. Lancet. 2003 Jul;362(9380): 316-22.

7 Henriksen JH, Gøtze JP, Fuglsang S, Christensen E, Bendtsen F, Møller S. Increased circulating pro-brain natriuretic peptide (proB$\mathrm{NP}$ ) and brain natriuretic peptide (BNP) in patients with cirrhosis: relation to cardiovascular dysfunction and severity of disease. Gut. 2003 Oct;52(10):1511-7.

8 Padillo J, Rioja P, Muñoz-Villanueva MC, Vallejo JA, Ciria R, Muntane J, et al. BNP as marker of heart dysfunction in patients with liver cirrhosis. Eur J Gastroenterol Hepatol. 2010 Nov;22(11):1331-6.

9 Pimenta J, Paulo C, Gomes A, Silva S, RochaGonçalves F, Bettencourt P. B-type natriuretic peptide is related to cardiac function and prognosis in hospitalized patients with decompensated cirrhosis. Liver Int. 2010 Aug; 30(7):1059-66.

10 Wong F, Siu S, Liu P, Blendis LM. Brain natriuretic peptide: is it a predictor of cardiomyopathy in cirrhosis? Clin Sci (Lond). 2001 Dec;101(6):621-8.

11 Yildiz R, Yildirim B, Karincaoglu M, Harputluoglu M, Hilmioglu F. Brain natriuretic peptide and severity of disease in non-alcoholic cirrhotic patients. J Gastroenterol Hepatol. 2005 Jul;20(7):1115-20.

12 Lang RM, Badano LP, Mor-Avi V, Afilalo J, Armstrong A, Ernande L, et al. Recommendations for cardiac chamber quantification by echocardiography in adults: an update from the American Society of Echocardiography and the European Association of Cardiovascular Imaging. Eur Heart J Cardiovasc Imaging. 2015 Mar; 16(3):233-70.
13 Russo C, Hahn RT, Jin Z, Homma S, Sacco RL, Di Tullio MR. Comparison of echocardiographic single-plane versus biplane method in the assessment of left atrial volume and validation by real time three-dimensional echocardiography. J Am Soc Echocardiogr. 2010 Sep;23(9):954-60.

14 Nagueh SF, Smiseth OA, Appleton CP, Byrd BF 3rd, Dokainish H, Edvardsen T, et al. Recommendations for the Evaluation of Left Ventricular Diastolic Function by Echocardiography: An Update from the American Society of Echocardiography and the European Association of Cardiovascular Imaging. J Am Soc Echocardiogr. 2016 Apr;29(4):277-314.

15 McCullough PA, Omland T, Maisel AS. Btype natriuretic peptides: a diagnostic breakthrough for clinicians. Rev Cardiovasc Med. 2003;4(2):72-80.

16 Mair J, Hammerer-Lercher A, Puschendorf B. The impact of cardiac natriuretic peptide determination on the diagnosis and management of heart failure. Clin Chem Lab Med. $2001 \mathrm{Jul} ; 39$ (7):571-88.

17 Packer M. Should B-type natriuretic peptide be measured routinely to guide the diagnosis and management of chronic heart failure? Circulation. 2003 Dec;108(24):2950-3.

18 Hartmann F, Packer M, Coats AJ, Fowler MB, Krum H, Mohacsi P, et al. NT-proBNP in severe chronic heart failure: rationale, design and preliminary results of the COPERNICUS NT-proBNP substudy. Eur J Heart Fail. 2004 Mar;6(3):343-50.

19 Campbell DJ, Mitchelhill KI, Schlicht SM, Booth RJ. Plasma amino-terminal pro-brain natriuretic peptide: a novel approach to the diagnosis of cardiac dysfunction. J Card Fail. 2000 Jun;6(2):130-9.

20 Wiese S, Mortensen C, Gøtze JP, Christensen E, Andersen O, Bendtsen F, et al. Cardiac and proinflammatory markers predict prognosis in cirrhosis. Liver Int. 2014 Jul;34(6):e19-30.
21 Pateron D, Beyne P, Laperche T, Logeard D, Lefilliatre P, Sogni P, et al. Elevated circulating cardiac troponin I in patients with cirrhosis. Hepatology. 1999 Mar;29(3):640-3.

22 Pozzi M, Carugo S, Boari G, Pecci V, de Ceglia S, Maggiolini S, et al. Evidence of functional and structural cardiac abnormalities in cirrhotic patients with and without ascites. Hepatology. 1997 Nov;26(5):1131-7.

23 Finucci G, Desideri A, Sacerdoti D, Bolognesi M, Merkel C, Angeli P, et al. Left ventricular diastolic function in liver cirrhosis. Scand J Gastroenterol. 1996 Mar;31(3):279_ 84.

$24 \mathrm{Ma}$ Z, Lee SS. Cirrhotic cardiomyopathy: getting to the heart of the matter. Hepatology. 1996 Aug;24(2):451-9.

25 Rabie RN, Cazzaniga M, Salerno F, Wong F. The use of E/A ratio as a predictor of outcome in cirrhotic patients treated with transjugular intrahepatic portosystemic shunt. Am J Gastroenterol. 2009 Oct; 104(10):2458-66.

26 Alexander J, Mishra P, Desai N, Ambadekar S, Gala B, Sawant P. Cirrhotic cardiomyopathy: indian scenario. J Gastroenterol Hepatol. 2007 Mar;22(3):395-9.

27 Merli M, Calicchia A, Ruffa A, Pellicori P, Riggio O, Giusto M, et al. Cardiac dysfunction in cirrhosis is not associated with the severity of liver disease. Eur J Intern Med. 2013 Mar; 24(2): 172-6

28 Nazar A, Guevara M, Sitges M, Terra C, Solà E, Guigou C, et al. Left ventricular function assessed by echocardiography in cirrhosis: relationship to systemic hemodynamics and renal dysfunction. J Hepatol. 2013 Jan;58(1): 51-7.

29 Sampaio F, Pimenta J. Left ventricular function assessment in cirrhosis: current methods and future directions. World J Gastroenterol. 2016 Jan;22(1):112-25. 